\title{
Psicologia e história no pensamento social de Manoel Bomfim
}

\section{Psychology and history in social thought of Manoel Bomfim}

\section{Francisco Teixeira Portugal*}

Professor Adjunto do Departamento de Psicologia Social e do Programa de Pósgraduação em Psicologia da Universidade Federal do Rio de Janeiro - UFRJ, Rio de Janeiro, RJ, Brasil

\begin{abstract}
RESUMO
Este artigo disserta sobre categorias relevantes para a psicologia conforme elaboradas por Manoel Bomfim nas primeiras décadas do século XX. Bomfim teceu considerações conceituais ricas para uma abordagem histórica e social da psicologia. Seu livro central de psicologia advoga em defesa de uma concepção processual de psiquismo suplantando de maneira eloquente algumas dicotomias que marcaram a institucionalização das abordagens psicológicas nas universidades dividindo e reificando os aspectos individuais e os sociais, biológicos e psíquicos. O trabalho termina indicando como essas propostas revelam no plano conceitual de uma psicologia seu envolvimento com projetos coletivos relacionados à vida republicana e à função da educação.

Palavras-chave: Manoel Bomfim, Psicologia, Pedagogium, Primeira República, Educação.
\end{abstract}

\section{ABSTRACT}

This paper argues that it is important to reacess some psychological categories as thought by Manoel Bomfim in the early years of $20^{\text {th }}$ century. Bomfim has shaped rich psychological conceptualizations in regard of its historical and social aspects. His major psychological work advocates a processual proposal of the mind allowing us to cease some of the remarkable oppositions still existent in psychology. They have been important since the institutionalization of the psychological field at the universities and they had put aside individual and socials aspects, as well as biological and psychological ones. This paper concludes showing how his psychological proposals reveal his engagement to social programs related to republican principles and educational projects.

Keywords: Manoel Bomfim, Psychology, Pedagogium, First Republic, Education. 
“Tanto como a linguagem, a história tem de ser investigada, sistematicamente analisada, por aqueles que desejem conhecer os processos da atividade psíquica."

Manoel Bomfim, 1923

Há pouco mais de uma década raros eram os trabalhos que evocavam seriamente alguma reflexão ou participação de Manoel Bomfim em seus argumentos centrais. Entre eles, há o livro de Dante Moreira Leite (1954), breve menções em Alfredo Bosi (1965), uma análise das idéias socialistas no Brasil por Vamireh Chacon (1965), um opúsculo de Aluizio Alves Filho (1979), uma seleção de textos do pensador com uma alentada e aprofundada introdução feita por Ricardo Ventura e Flora Sussekind (1984), um artigo de Antonio Candido (1973) e dois artigos de Mitsuko Antunes (1996, 1997). Outros poucos trabalhos com breves menções ao autor podem ser indicados (Olinto, 1944; Penna, 1972). É possível encontrar referências diretas, na forma de prefácios e coletâneas, como a seleção de textos de Bomfim organizada por Carlos Maul em 1935, poucos anos após seu falecimento, o prefácio da segunda edição do livro América Latina: males de origem (1936) feito por Azevedo Amaral, reproduzido na terceira edição (1993) e acompanhado de comentários de Darcy Ribeiro e de Franklin de Oliveira. Raras são também, na já rica historiografia da Psicologia no Brasil produzida nas duas últimas décadas, as referências a Manoel Bomfim e as análises das relações entre educação e psicologia na Primeira República.

Tal estado da arte levou a comentários, daqueles que julgavam relevante a obra de Manoel Bomfim, a lamentar e denunciar seu esquecimento (ALVES FILHO, 1979; ANTUNES, 1996; AGUIAR, 2000). A reedição em 1993 de seu livro mais conhecido é acompanhada por um crescente interesse em sua obra e, se ainda correspondia à carência de referências e reflexões sobre seu papel na história do Brasil nos textos produzidos até a década de 1990 o qualificativo de esquecido, tal situação não reflete mais a situação atual. Ao longo da última década pelo menos uma dezena de teses e dissertações foram defendidas em variados programas de pós-graduação de diferentes áreas (ciências sociais, história, educação, geografia, psicologia e, até mesmo, engenharia), algumas delas tendo se transformado em livros, novas edições de sua obra vieram à luz mais de sessenta anos após sua morte e vários artigos sobre o tema foram publicados em periódicos relevantes.

Entretanto, com exceção dos trabalhos eruditos de Leite (1954), os de 
Antunes (1996, 1997, 1998, 2001) e das breves menções à relevância do autor (PENNA, 1992; JACÓ VILELA, 1999; AGUIAR, 2000; BOMFIM, 2003) sua obra psicológica continua bastante desconhecida mesmo entre os historiadores da Psicologia. Na extensa e cuidadosa biografia escrita por Aguiar (2000) a Psicologia de Bomfim figura apenas em breves citações como resultado de uma entrevista a Antonio Gomes Penna feita pelo autor em que Penna reproduz em linhas gerais o que já havia escrito em 1992 em seu livro História da Psicologia no Rio de Janeiro (AGUIAR, 2000, p. 255 e 454).

É necessário ressaltar que entre os movimentos contemporâneos da Psicologia brasileira para instituir uma memória de seu passado, a segunda edição do principal livro de psicologia de Manoel Bomfim, Pensar e dizer: estudo do símbolo no pensamento e na linguagem, em 2006 foi um marco na retomada das reflexões sobre a relevância de sua obra psicológica. ${ }^{1}$

É diante desse quadro de crescente interesse pela obra e vida de Manoel Bomfim, acompanhado da relativa escassez de uma avaliação mais aprofundada das contribuições e valor de sua obra psicológica, que essa reflexão se insere. Trata-se também, por extensão, de investigar o papel das ciências, em especial do saber psicológico, para as transformações sociais em curso nas quatro décadas da Primeira República do Brasil.

\section{O Pedagogium, a educação e a psicologia na Primeira República} As análises históricas e sociológicas relativas à obra do pensador sergipano estão centradas em dois conjuntos de textos. O primeiro é formado por seu livro mais conhecido, América Latina: males de origem (1905) e o segundo pela trilogia O Brasil na América: caracterização da formação brasileira (1929), O Brasil na história: deturpação dos trabalhos, degradação política (1931) e O Brasil nação: realidade da soberania brasileira (1931). Seus trabalhos sobre psicologia e, também, pedagogia, figuram em segundo plano, se e quando são citados. Cabe indicar aqui que esses trabalhos constituem parte bastante extensa e significativa da bibliografia do autor e, além disso, são absolutamente coerentes com sua atuação profissional de diretor geral do Pedagogium por dezessete anos (de 1896 a 1905 e de 1911 a 1919, ano em que ocorreu a extinção da instituição). Assim, podemos indicar como textos inequivocamente psicológicos as seguintes publicações Das alucinações auditivas dos "perseguidos" (1904), O fato psíquico (1904)², O ciúme (1905), Noções de psicologia (1917), Pensar e dizer: estudo do símbolo no pensamento e na linguagem (1923) e O método dos testes: com aplicações à linguagem do ensino primário (1928). Sobre pedagogia há 
Lições de pedagogia: teoria e prática da educação (1915) - um alentado volume resultante das aulas de pedagogia e psicologia proferidas no Pedagogium - além de diversos outros textos que constituem matérias de periódicos, discursos e material didático para uso nas escolas (o livro Através do Brasil, escrito para uso didático e em colaboração com Olavo Bilac e publicado pela primeira vez em 1910, teve mais de sessenta edições até 1962 (cf. AGUIAR, 2000, p. 523).

Levanto a hipótese que esse desconhecimento tem sido efeito de dois fatores: uma imagem da Psicologia corrente entre historiadores e cientistas sociais que a restringe ao campo de análises individuais e de um psiquismo concebido como atributo do indivíduo (neste sentido, em que a Psicologia poderia contribuir para o conhecimento histórico e as questões sociais?), e a idéia de que a Psicologia se limitaria a produzir um arsenal técnico e instrumental para solução de problemas e desvios psicológicos emergentes entre os sujeitos. A esse propósito convém indicar as razões evocadas por Aguiar (2001, p. 254, n. 306) para não discutir ou avaliar a obra psicológica de Manoel Bomfim: "isso fugiria inteiramente ao campo de interesse específico desta biografia sociológica." (grifos acrescentados).

Imagem certamente tributária da oposição entre sociologia e psicologia tão fortemente estabelecida no início do século XX que cavou um fosso entre as dimensões social e individual, provocando, por demasiado tempo, um isolamento entre esses campos disciplinares. As abordagens psicossociológicas e as vertentes da Psicologia Social contemporânea tem, por meio de análises históricas de sua constituição, possibilitado escapar dessa dicotomia (FARR, 2001). Não devemos deixar de evocar aqui as reflexões sobre a historiografia da psicologia moderna que tão enfaticamente têm salientado a necessidade de situar o processo psíquico tanto no contexto da vida individual como no centro das matrizes socioculturais do período em questão (BROZEK; MASSIMI, 1998).

Sugeri a hipótese de uma exclusão prévia dos textos psicológicos de Bomfim nas análises históricas e sociológicas que abordaram sua obra para salientar o conjunto de formulações sociais avessas à dicotomia entre indivíduo e coletividade presente no livro Pensar e dizer: o estudo do símbolo no pensamento e na linguagem (1923), certamente seu livro de Psicologia de maior fôlego e elaboração teórica. Tais formulações podem recolocar algumas questões suscitadas nas referidas análises enriquecendo não apenas sua obra mas o conhecimento do período em questão. São elas: a defesa da educação como meio de transformação social, a questão da identidade nacional e sua relação com a língua, o evolucionismo simbólico e suas consequências tanto para a terminologia 
biológica corrente nas obras do autor quanto para sua posição antirracista.

Bomfim formou-se em medicina pela Faculdade de Medicina do Rio de Janeiro com a tese Das nefrites (1890), mas sua carreira médica foi curta, tendo sido logo substituída por sua longa atuação no campo da educação como diretor geral do Pedagogium. Designado por Medeiros e Albuquerque, então Diretor da Instrução Pública, para exercer esta função na qual, havia aproximadamente seis meses, já ocupava o cargo de subdiretor, Manoel Bomfim atuou, até a extinção da instituição, em defesa da educação pública.

O Pedagogium foi instituído a partir da proposta de criação de um museu pedagógico nacional conforme parecer de Rui Barbosa em 1882 ao projeto de reforma de ensino de Rodolfo Dantas. Fundado em 1890, tinha como funções a coordenação e o controle das atividades pedagógicas no país. Seu caráter centralizador conflitou, segundo Aguiar (2000, p. 189), com a política descentralizadora da Constituição republicana de 1891 quanto à instrução. Se esse conflito, entre outros fatores, levou a uma certa inatividade da instituição durante seus primeiros seis anos, houve, contudo, sob a direção de Menezes Vieira, a publicação da Revista Pedagógica, orgão oficial da instituição e material histórico de significativa relevância.

O Pedagogium e a Revista Pedagógica constituem novas formas de atuação, no tocante à educação, consoante ao ideário defendido pelos intelectuais da Geração de 70, tão presente na transição do Império para a Nova República. Os princípios do projeto republicano para reformar a instrução pública eram a laicidade, a gratuidade do ensino primário, a liberdade de ensino e a ciência como fundamento da organização curricular e do ensino propriamente dito (FERNANDES, 2006; GONDRA, 2001) e expressavam os desígnios, mais gerais, orientadores da perspectiva republicana de modernização e civilização do país (KROPF, 1994; HERSCHMANN; PEREIRA, 1994).

Para implementar a construção desse Brasil moderno, que se inseriria no berço das nações civilizadas, a noção de progresso foi constantemente evocada como suporte da possibilidade de regeneração da realidade brasileira e ruptura com seu passado pré-republicano. É nesse contexto que o positivismo e o evolucionismo amparam a noção de progresso e orientam as ações de reforma do Brasil.

Há material substancial sobre os efeitos normatizadores, hierarquizantes e modeladores do período em diferentes campos como a medicina social (SCHWARCZ, 1993; COSTA, 1979), a psiquiatria (MACHADO; LOUREIRO; LUZ; MURICY, 1978), as reformas do espaço urbano (HERSCHMANN; PEREIRA, 1994), a educação (FREITAS; KUHLMANN 
JR., 2002; MONARCHA, 2001) e também ao papel do emergente saber psicológico que então vinha atrelado à educação ou às práticas médicas (ALBERTI, 2003). Propomo-nos a inserir nessas discussões, especialmente no campo da educação em suas relações com a psicologia, alguns aspectos do trabalho de Bomfim que escapam ao discurso hegemônico à época. O evolucionismo simbólico defendido pelo autor com suas consequências antirracistas e a defesa da educação fora das perspectivas positivista e evolucionista dominantes são aspectos relevantes. Contudo, o que surpreende nessas elaborações é justamente a concepção de Psicologia elaborada por Bomfim e seu papel no encaminhamento das questões levantadas acima.

Assim, longe de conceber a Psicologia como ciência capaz de produzir um conjunto de técnicas que permitiriam a otimização da educação e do controle dos indivíduos, Bomfim enfatiza, de modo bastante original e altissonante, a natureza social do psiquismo. Pensar e dizer (1923) constitui, neste sentido, uma rica elaboração conceitual em defesa da formação coletiva do espírito. Fato bastante surpreendente se considerarmos que sua ida à França, nos primeiros anos do século XX, foi para travar conhecimento com as teorias psicológicas de então com Binet, o grande pesquisador dos testes psicológicos, que supervisionou, à distância, a construção do primeiro laboratório de psicologia experimental no Brasil, construído no Pedagogium, quando do retorno de Bomfim ao Rio de Janeiro. Em lugar de encontrarmos tentativas de utilização dos resultados das investigações no laboratório de psicologia experimental como instrumento de aprimoramento da educação, encontramos críticas severas ao procedimento experimental em Psicologia tanto na obra de 1923 quanto no livro O método dos testes de 1928.

Uma análise preliminar da Revista Pedagógica indica referências constantes tanto a Spencer quanto a Comte. Sabemos que um dos principais pressupostos da ação positivista na educação estribou-se na crença positivista de que a ciência, pela elaboração de instrumentos eficazes de intervenção, pode regenerar a sociedade. Mas foi em franca oposição a essa orientação que Bomfim teceu amplas considerações nessas duas obras; resta saber o quanto esta posição estava presente no dia-a-dia de seu trabalho no Pedagogium. Gontijo (2003) observa ainda que a defesa da neutralidade científica presente nos discursos dos intelectuais e políticos desse período, fortemente inspirados no positivismo, foi frontalmente rejeitada por Bomfim que preferiu deixar claro o engajamento (e o rigor) de suas reflexões e consequências políticas. Mais ainda, denunciou a neutralidade científica como um instrumento de dominação na mão dos que defendiam as teorias 
racistas e propunham o branqueamento das raças ou justificavam a espoliação de uma nação por outra "mais civilizada".

A investigação da obra psicológica e pedagógica de Bomfim permite ainda problematizar outros aspectos levantados por seus comentadores. Analistas da obra do sergipano ressaltam a moderação e a contenção da proposta educacional por ele elaborada. Tal estilo estaria em clara oposição ao tom iconoclasta, polêmico e incisivo próprio ao autor quando discorre sobre outros temas. Candido (1990, p. 17) chamou "visão ilustrada" a crença - então difundida entre intelectuais - de que a "instrução seria o remédio suficiente para redimir as massas." Esse posicionamento contituiu, ainda segundo Candido, uma atenuação do radicalismo presente em sua obra e revelaria o recuo de Bomfim da radical defesa da revolução como forma de combater a dominação tão extensamente denunciada tanto em América Latina: males de origem (1905) quanto na trilogia sobre o Brasil (BOMFIM, 1929, 1930, 1931). Ventura e Sussekind (1984) optaram por não criticar Bomfim em função de sua crença na educação como solução dos problemas sociais, uma vez que da educação como "cura", defendida em 1905, ele deixa claro, mais de vinte anos depois, sua opção pela revolução como forma de suplantar os males sociais provocados pelas nações "parasitárias" e "salteadoras", termos caros ao autor. Em um elaborado deslocamento, Ventura e Sussekind apontam que criticável em Bomfim foi a manutenção, simultaneamente à defesa da revolução, da noção de nação e do biologismo como forma de interpretação da história e da sociedade brasileiras. Tocamos aqui em outro ponto que a obra psicológica do autor parece contribuir para a discussão: o biologismo de suas reflexões e a inibição na produção de um aparato conceitual próprio.

Desde a indicação do biologismo, fruto de análise centrada principalmente no texto de 1905, feita por alguns de seus analistas (CANDIDO, 1973; KROPF, 1996; GONTIJO, 2003) até a ampla e aprofundada investigação levada a cabo por Ventura e Sussekind (1984), os textos psicológicos continuam ausentes. Sabemos que Botelho (2003) promoveu deslocamento para a questão da educação conferindo-lhe o papel de libertadora do paradigma biológico vigente. Entretanto, a referência ao livro Pensar e dizer presente naquele texto restringe-se a exemplificar livros didáticos produzidos por Bomfim.

Ao conjugar a interpretação social de Bomfim própria ao América Latina. Males de origem (1905) com Pensar e dizer. Estudo do símbolo no pensamento e na linguagem (1923), fica claro que as teorias raciais constituem, para o educador, um recurso para dominação por determinados grupos sociais. O evolucionismo que as acompanha foi 
também objeto de uma interpretação inovadora na obra psicológica. Tomando como parâmetro de evolução a capacidade de abstração - que na linguagem tem como exemplo maior, segundo o autor, a atividade poética ao produzir novas imagens e novas estruturas -, Bomfim torna a questão racial secundária em relação à atividade social dos indivíduos. O processo educativo, formador, e a atividade social dos integrantes de uma determinada tradição (termo do autor para representar uma determinada ordem simbólica e social) são dinâmicos. Se por um lado eles atuam na uniformização dos indivíduos que compõem um agrupamento social, por outro, a própria dinâmica da evolução social os mantém como agentes políticos. A dicotomia determinismo biológico e construcionismo social não se sustenta já que o evolucionismo congrega aspectos biológicos e sociais em relação mútua.

\section{A psicologia e a história}

Um dos principais pressupostos da psicologia contemporânea tem sido o indivíduo. Sabemos que ele tem sua origem histórica em movimentos, principalmente no século XIX, que transcendem a psicologia, como as novas formas de gestão do Estado, novas práticas sociais que se sistematizaram em ciências humanas e sociais, nova configuração das grandes cidades e mudanças tecnológicas, entre outras. Nem por isso sua importância na psicologia decresceu. Em lugar disso, podemos dizer que esta noção continua operando nas práticas psicológicas contemporâneas.

Seu sucedâneo, o individualismo, na versão francesa e inglesa, principais referências das novas idéias que povoavam a nova República, referia-se tanto ao isolamento social, moral e político de indivíduos desenraizados, opostos ao controle social, voltados para a acumulação e refratários aos ideais socializantes, quanto ao liberalismo com sua defesa do Estado mínimo que encoraja a competição e o valoriza a "livre" e desimpedida iniciativa, expressão da liberdade individual (LUKES, 1973).

São, principalmente, os autores franceses, ingleses e americanos as referências de Bomfim em seu projeto de psicologia. Neste contexto, curiosamente, o livro Pensar e dizer (1923) está na contracorrente da individualização e naturalização próprias à Psicologia experimental então emergente. Antes mesmo de realizar tal leitura da obra de Bomfim vale anunciar que ela carrega uma tensão. Apesar de defender muito evidentemente uma psicologia social e histórica, sua terminologia impressão, excitação, sensação, percepção, representação, imagem, idéia, atenção, associação de idéias, abstração, generalização - , retirada do arcabouço teórico da psicologia individualista de então, gera 
dificuldades e contrasensos, já que todo conceito carrega uma história e um afunilamento. Há, ainda, um confronto nesse mesmo sentido entre o livro Noções de Psicologia (1917), escrito com finalidade pedagógica para ser um manual de Psicologia destinado ao curso Normal, e Pensar e dizer, texto de maior alcance e mais propositivo. O esquematismo do primeiro reproduz, em maior ou menor parte, a concepção individualista vigente na psicologia enquanto o segundo, com um tom mais reflexivo, filia-se a uma proposta processual.

Convém marcar que não está sendo buscado aqui, entre tantas possibilidades, a unidade da obra do autor, pois, como afirmou Certeau (2000), essa unidade se presta à discussão. Não é a concepção individualista que subsume a identidade da obra ao fato dela ter sido produzida por um mesmo autor, a solução do problema. A unidade resulta muito mais da operação do historiador que de uma realidade apreensível no objeto. Feita essas ressalvas, a análise aqui realizada está centrada no livro de 1923, Pensar e Dizer.

Bomfim concebe o psiquismo como essencialmente socializado, como função da comunicação interindividual. Em lugar de uma psique concebida como estrutura prévia às relações do indivíduo com o meio cósmico, as expressões do psiquismo são as próprias formas da interação humana socializada. Assim é que o espírito não se confunde com o indivíduo.

O espírito não é o indivíduo no isolamento de sua consciência; nem haveria o aspecto consciência, se esta se isolasse. O espírito é a consciência em função social, como refração ativa de tudo que concorre na tessitura da sociedade. (BOMFIM, 1923, p. 8-9)

O propósito do livro é assinalar o papel do símbolo na vida consciente na medida em que o espírito "se realiza como unidade ativa de um conjunto, ao qual está intimamente ligado, e de que depende de modo absoluto, a sociedade." (BOMFIM, 1923, p. 17) Está em questão a dissolução da oposição entre indivíduo e sociedade na experiência psíquica. Se há um corpo, um indivíduo biológico parte de um conjunto, de uma espécie, por outro lado a consistência do espírito, sua realidade, não é nem anterior nem oposta à vida social, mas sua expressão.

A consciência se forma no assimilar o meio social; a esse meio conjuga as suas forças, de tal sorte que nem nos é possível compreender a existência da criatura humana fora daí. I sole-se o indivíduo da vida social; faça-se a abstração do que, na sua psicologia, se liga às formas históricas ou tradicionais, e essa psicologia se reduzirá ao milionésimo do que era. (BOMFIM, 
1923, p. 17) De tudo isso [da incompletude de orientações biológicas herdadas], resulta que a parte característica, e essencialmente humana, nas vicissitudes da consciência, é o reflexo e a interferência das influências sociais. (BOMFIM, 1923, p. 18)

A assimilação da experiência psíquica às atividades sociais relaciona-se à centralidade do símbolo na vida do espírito. A linguagem é concebida como o aspecto sensível da vida do espírito, ponto de convergência de toda atividade psíquica e da própria consciência. Não se trata de uma concepção psicologista da linguagem em que ela surge como um atributo ou uma ferramenta à disposição de um psiquismo, pois o autor se recusa concebê-la como mera "roupagem" de um pensamento que busca se expressar, ou como uma "forma em que o pensamento vem se meter". A linguagem é "o regime lúcido e expressivo da atividade mental", isto é, o aspecto sensível do pensamento. (BOMFIM, 1923, p. 8)

O símbolo tem relevância porque é o ponto de convergência das consciências individuais e das formações coletivas. A vida do espírito em seu aspecto ativo, seu aspecto processual e interativo estabiliza, na história, o indivíduo e a sociedade. Como aspecto sensível da atividade mental, o símbolo não é reduzido nem ao psicologismo corrente, nem ao sociologismo. Evitando o psicologismo, o símbolo não emana de uma consciência individual cuja existência o antecede. Não cabe aqui a consideração de uma estrutura psíquica imutável cujas formas históricas modificariam apenas o verniz dessa estátua. A proposta, radical ainda hoje, é a de que o espírito se constitui no fluxo das relações simbólicas próprias ao curso histórico-social. Recusando também o sociologismo, a simbólica não se apresenta aprioristicamente ou tem seu curso de forma absolutamente autônoma em relação ao espírito.

Não se trata de elucidar os determinantes individuais e psicológicos da linguagem próprios a um sujeito universal, nem mesmo buscar uma explicitação estrutural das variações sociais em alguma entidade social independente do espírito. À história é destinado o papel de ordenar as experiências tanto individuais como coletivas. "A psicologia humana é, sobretudo, o viver social, refletido em atividades na consciência individual; a sociologia é a atividade psíquica, coordenada no viver social; todo fato social tem, por isso mesmo, um correlato nas psicologias individuais." (BOMFIM, 1923, p. 21)

Nesse sentido, diferentes experiências históricas, no jogo das relações que Ihes são próprias, instituem novas ordenações simbólicas que expressam tanto as novas formas do viver social, as tradições na terminologia de Bomfim, quanto as experiências individuais. 
A simbólica, noção-dobradiça operando entre o individual e o coletivo, fruto da vida de relação, da interação socialmente organizada, torna-se um conceito chave para essa psicologia social. Assim, surge o nome João Ribeiro evocado por reclamar para nós "o direito de ter um idiomatismo próprio" ainda que restrito ao âmbito da gramática e da filosofia "em que é mestre". Esse reclamo tem a função não apenas de garantir uma diferença voltada para a independência política que era própria à nação, mas também, e simultaneamente, uma independência do próprio espírito que aí se expressa. A defesa de uma língua própria garante tanto "uma existência distinta, como povo", "uma tradição nacional", uma soberania; como um pensamento e "se nos corrigimos, em atenção aos eruditos, «estamos de fato a mutilar idéias e sentimentos, que nos são pessoais. Já não é a língua que apuramos, é o nosso espírito que sujeitamos a um servilismo inexplicável. "3" (BOMFIM, 1923, p. 9)

A diferenciação das línguas é então positivada e defendida no jogo da enunciação e da sistematização, da diacronia e da sincronia. A língua, na realidade da existência social, é "a própria vida do pensamento", "a organização do espírito", mas se institui também "como formação primeira de cada tradição humana; realiza-se numa estrutura viva, nimiamente ativa, desenvolvendo-se, evoluindo, expandindo-se, refazendo-se, progredindo e fortalecendo-se, como se desenvolve e evolui e se expande e se refaz e progride o próprio espírito." (Bomfim, 1923, p. 10). A língua expressa e consubstancia tanto o espírito como a tradição, recusando-se a isolar indivíduos de coletivos. O aspecto sistemático da língua, ainda que presente nas tradições, é objeto de severas críticas. Pois aqueles que se ocupam da "estrutura fonética dos vocábulos", os que exercem "o pedantismo da erudição vernacular" sentem-se bem com uma fauna e flora de cadáveres, constituem "seres vivos, apenas capazes de aproveitar o que está a decompor-se". O movimento e a atividade da língua é o que, sobretudo, interessa a Bomfim. "Figuremo-la [a língua] como a transparência de uma organização que se tece em fios animados e luminosos, ânimo e luz que são da sua essência mesma: a vida do espírito" (BOMFIM, 1923, p. 10). Movimento igualmente presente no pensamento, aspecto mais silencioso do espírito. "Há um regime de linguagem que deixa transparecer, sobretudo, o que é ativo e móbil no pensamento, e que o acompanha facilmente, ao pensamento, em todos os seus surtos e suas expansões. É, por isso, a linguagem nimiamente propícia à evolução das abstrações, e às sínteses de conhecimentos; é a linguagem onde fácil e lucidamente se simbolizam as discriminações do espírito, para a perfeita distribuição das categorais mentais" (BOMFIM, 1923, p. 12). 
Ressaltada a perspectiva histórica para investigação psicológica pela valorização da linguagem, dois temas ganham nova luz, a educação e o evolucionismo.

É a ausência, nas relações humanas com seu entorno, de formas instintivas, herdadas pelas gerações, que nos obriga a "recebê-las da tradição social, mediante a educação." As tradições condensam experiências realizadas pela espécie ao longo da história constituindo um arcabouço comum e com funções econômicas. Se o argumento parece ecoar o darwinismo na formulação de Haeckel - a ontogênese reproduz a filogênese - a noção evocada é a da imitação na diversidade de concepções. Tarde, Bagehot e Baldwin surgem com função legitimadora, pois no que diz respeito à imitação há diferenças significativas entre eles. Em Bomfim, as experiência históricas organizam-se nas sociedades, pelas simbólicas e tradições. É a imitação o processo de educação, de formação social do espírito. "O homem realiza sua maravilhosa formação «assimilando, por imitação, a sociedade que o recebe e o educa»" (BOMFIM, 1923, p. 31)

O sentido de educação tem, nessa obra, uma conotação muito ampla dizendo respeito ao conjunto de experiências sociais que constituem a vida do espírito. Nessa direção, a educação evoca processos horizontais e dispersos na trama simbólica das sociedades e a citação de As leis da imitação de Tarde nesse momento deixa aberta a possibilidade de investigar outros dispositivos de formação de tradições além do regime educacional organizado e formal próprio ao Estado.

A educação como processo formal de instrução e formação, ligada aos processos geridos pelo Estado na organização da população envolveria, como afirmou Candido (1990), uma visão ilustrada por parte de Bomfim. Se as metáforas biológicas do América Latina. Males de origem permitiam evidenciar os processos de dominação entre os colonizadores europeus e os colonizados sul-americanos, a defesa da educação concebida como processo social de transmissão das tradições, própria a Pensar e dizer, conferiu um tom novo à questão, já que afirmava a diferença entre as nações e sua necessária autonomia em franca oposição às teses da inferioridade biológica da raça e, por extensão, da nação. Tratava-se de um afastamento da crença em um projeto de regeneração social pela via liberal e democrata, mas mantinha, ainda que com novas cores, a defesa da nação como horizonte a ser alcançado. O horizonte de ação consistia então em sedimentar uma simbólica própria à nação apoiada também pelos processos formais da instrução pública. Posição de um otimismo nacionalista, é certo, mas decorrente, em grande parte, do papel aberto da história nas transformações sociais. A revolução é claramente defendida em O Brasil 
Nação (1931), em que o autor considera retrospectivamente a inanidade de sua precedente proposta educacional como "cura" dos males da nação, em reconhecimento de que os males são também provocados por agentes internos, opondo diferentes "classes" sociais e inibindo qualquer renovação.

Convém lembrar que, concomitantemente às análises biológicas que opuseram parasitados e parasitas, ressaltando desse forma as relações de dominação, há um claro evolucionismo em Bomfim. Ainda que, em lugar de naturalizar o social, seu evolucionismo opere sobre o nível simbólico mais que sobre o natural, há um vetor qualitativo nas relações sociais.

A manutenção da noção de nação encontra aqui uma de suas justificativas. A nação, e seu povo, é garantida pela tessitura simbólica em que a língua representa a forma principal. Passando ao largo das dificuldades em garantir uma identidade nacional pela comunidade linguística, o ponto a ser considerado diz respeito ao deslocamento de conceito de raça e seus dinamismos nos destinos da nação para o de símbolo.

A evolução preconizada por Bomfim diz respeito às transformações históricas das tradições sociais. Seu caminho e também o critério de evolução é a abstração. "Consideremos agora que o pensamento humano fez, e faz, a sua evolução numa ascenção constante de abstrações; donde a necessidade de se abandonarem os sinais diretos, substituídos pelos símbolos puros." (BOMFIM, 1923, p. 35) Dessa forma, a evolução diz respeito à simbólica, às tradições que ao longo da história constroem, pela abstração dos sinais diretos, símbolos "puros". Aqui, novamente a educação tem uma função, a de difundir as experiências historicamente constituídas e sedimentadas nos símbolos.

A psicologia de Bomfim, escrita após sua saída do Pedagogium e sem um diálogo disciplinar, em grande parte ausente, já que era sobretudo o discurso psiquiátrico a forma dominante do campo psi, se inscreve, por seu conjunto de proposições, nas preocupações sociais. Mesmo que estas não sejam explícitas como em seus textos históricos, seus conceitos demandam e pressupõem o lugar da história na constituição do espírito. Assim, em lugar de fomentar uma discussão instrumental e individualista, corrente nas preocupações de caráter psicológico de seus contemporâneos, Bomfim deslocou seus eixos de reflexão e atuação para o conjunto das preocupações sociais, aproximando história, psicologia e educação. 


\section{Referências Bibliográficas}

ALBERTI, S. Crepúsculo da alma. A psicologia no Brasil no século XIX. Rio de Janeiro: Contra Capa, 2003.

AGUIAR, R. C. O rebelde esquecido. Tempo, vida e obra de Manoel Bomfim. Rio de Janeiro: Toopbooks, 2000.

ANTUNES, M. A. M. A Psicologia no Brasil. Leitura histórica de sua constituição. São Paulo: Unimarco Editora/Educ, 1996.

Manoel Bomfim, pensar e dizer: estudo do symbolo no pensamento e na linguagem, 1923: uma contribuição à memória da Psicologia brasileira. I nterações, v. 1, n. 1, p. 15-30, 1996.

. Uma interpretação do Brasil por Manoel Bomfim. Interações, v. 2, n. 4, p. 7-16, 1996.

Manoel Bomfim. In: CAMPOS, R.H.F. (Org.). Dicionário biográfico da psicologia no Brasil. Rio de Janeiro: I mago, 2001. BASTOS, M. H. C. Jardim de crianças: o pioneirismo do dr. Menezes Vieira (1875-1887). In: MONARCHA, C. (Org.). Educação da infância brasileira (1875-1983). São Paulo: Fapesp/Editora autores associados, 2001, p. 31-8.

BOMFIM, E. M. Psicologia social no Brasil. Belo Horizonte: Edições do Campo Social, 2003.

BOMFIM, M. Das alucinações auditivas dos "perseguidos". Rio de Janeiro: Tipografia Espíndola, 1904.

O fato psíquico. Rio de Janeiro: Tipografia Espíndola, 1904.

$\overline{1} \overline{9} \overline{0} \overline{5}$.

A América Latina. Males de origem. Rio de Janeiro: Garnier,

O respeito à criança. Discurso pronunciado como paraninfo de turma da Escola Normal de 1906 por Manoel Bomfim, 1906.

. Noções de psychologia. Rio de Janeiro: Francisco Alves, 1917. Disponível em <http://newpsi.bvs-psi.org.br/ebooks/bomfim.htm>. Acesso em: 8 dez. 2009.

- Pensar e dizer. Estudo do symbolo no pensamento e na linguagem. Rio de Janeiro: Casa Electros, 1923. Reeditado em 2006 pela editora Casa do Psicólogo patrocinado pelo Conselho Federal de Psicologia, Disponível em <http://newpsi.bvspsi.org.br/ebooks/bomfim.htm>. Acesso em: 8 dez. 2009.

. Lições de pedagogia. Theoria e prática da educação. Rio de Janeiro: Francisco Alves, 1926 (1915).

O método dos testes: com aplicações à linguagem do ensino primário. Rio de Janeiro: Francisco Alves, 1928. Disponível em <http://newpsi.bvs-psi.org.br/ebooks/bomfim.htm>. Acesso em: $8 \mathrm{dez}$. 2009.

. O Brasil na América: caracterização da formação brasileira. Rio 
de Janeiro: Francisco Alves, 1929.

- Brasil na história. Deturpação das tradições e degradação política. Rio de Janeiro: Francisco Alves, 1930.

O Brasil nação: realidade da soberania brasileira. Rio de Janeiro: Francisco Alves, 1931.

. Cultura e educação do povo brasileiro. Rio de Janeiro: Pongetti, 1932.

BOSI, A. A literatura brasileira. São Paulo: Cultrix, v. 6, 1935.

BOTELHO, A. Na contracorrente do naturalismo: relações sociais na interpretação do Brasil de Manoel Bomfim. Temáticas, v. 11, n. 21-22, p. 75-100, 2003.

BROZEK J.; MASSIMI, M. (Orgs.). Historiografia da Psicologia Moderna. São Paulo: Editora Unimarco e Edições Loyola, 1998.

CANDIDO, A. Literatura e subdesenvolvimento. Argumento, v.1, 1973.

. Radicalismos. Estudos Avançados, v. 4, n. 8, p. 4-18, 1990.

CAVALCANTI, J. B. U. Relatório apresentado ao Presidente da República dos Estudos Unidos do Brasil (Relatório). Rio de Janeiro: Imprensa Oficial, 1891.

CERTEAU, M. de. A escrita da história. Rio de Janeiro: Forense Universitária, 2000.

CHACON, V. História das idéias socialistas no Brasil. Rio de Janeiro: Civilização Brasileira, 1965.

COSTA, J. F. Ordem médica e norma familiar. Rio de Janeiro: Graal, 1979.

FARR, R. M. As raízes da psicologia social moderna. Petrópolis: Vozes, 2001 [1996].

FERNANDES, A. L. C. Educação, ciência e progresso: a Revista Pedagógica e o "problema social" do Brasil no final do século XIX. Revista Contemporânea de Educação, v. 1, n. 1, p. 11, 2006.

FOUCAULT M. Vigiar e punir. Nascimento da prisão. Petrópolis: Vozes, 1977.

FREITAS, M. C.; KUHLMANN JR., M. (Orgs.). Os intelectuais na história da infância. São Paulo: Cortez, 2002.

GONDRA, J. G. O veículo de circulação da pedagogia oficial da República: a Revista Pedagógica. Revista Brasileira de Estudos Pedagógicos, v. 78, n. 188/189/190, p. 374-394, 1997.

- Ecos da República: ciclo de vida e doutrina médica da Revista Pedagógica (1890-1896). Educação On-Line. Disponível em: <http://www.educacaoonline.pro.br/>. Acesso em: 3 mar. 2008. GONTIJO, R. Manoel Bomfim, "pensador da História" na Primeira República. Revista Brasileira de História. v. 23, n. 45, p. 129-154, 2003. 
JACÓ-VILELA, A. M. Análise inicial da produção escrita em Psicologia no Brasil. In: JACÓ-VILELA, A. M.; MANCEBO, D. (Orgs.). Psicologia social. Abordagens sócio-históricas e desafios contemporâneos. Rio de Janeiro: EdUerj, 1999, p. 91-108.

KROPF, S. P. O saber para prever, a fim de prover - a engenharia de um Brasil moderno. In: HERSCHMANN, M. ; PEREIRA, C. A. M. (Orgs.). A invenção do Brasil moderno: medicina, educação e engenharia nos anos 20 e 30. Rio de Janeiro: Rocco, 1994.

- Manoel Bomfim e Euclides da Cunha: vozes dissonantes aos horizontes do progresso. História, ciências, saúde - Manguinhos, v. 3, n. 1, p. 80-98, 1996.

KUHLMANN, JR., M. (2001) O jardim-de-infância e a educação das crianças pobres: ninal do século XIX, início do século XX. In C. Monarcha (Org.). Educação da infância brasileira (1875-1983). São Paulo: Fapesp/Editora autores associados, 2001, p.3-30.

LEITE, D. M. O caráter nacional brasileiro. São Paulo: Boletins da Faculdade de Filosofia, Ciências e Letras, n. 230, 1954.

LUKES, S. Types of individualism. In: Dictionary of the history of ideas. New York: Wilner, 1973.

MACHADO, R.; LOUREIRO, A.; LUZ, R.; MURICY, K. Danação da norma. Rio de Janeiro: Graal, 1978.

MEIRELLeS, H. (2007) Pedagogium. Sítio do Centro de Memória Institucional do ISERJ, 2007. Disponível em: <http://cemiiserj. blogspot.com/2007/08/pedagogium.html>. Acesso em: 22 fev. 2008.

MONARCHA, C. (Org.). Educação da infância brasileira (18751983). São Paulo: Fapesp / Editora autores associados, 2001.

OLINTO, P. A Psicologia Experimental no Brasil. In: ANTUNES, M. A. M. (Org. ). História da psicologia no Brasil. Rio de Janeiro: EdUerj, 2000. PENNA, A. G. História da psicologia no Rio de Janeiro. Rio de Janeiro: I mago, 1992.

SCHWARCZ, L. M. O espetáculo das raças. Cientistas, instituições e questão racial no Brasil 1870-1930. São Paulo: Companhia das Letras, 1993.

VENTURA, R.; SUSSEKIND, F. História e dependência: cultura e sociedade em Manoel Bomfim. São Paulo: Moderna, 1984.

\section{Endereço para correspondência}

Francisco Teixeira Portugal

Programa de Pós-Graduação em Psicologia da UFRJ, Av. Pasteur, 250, Pavilhão Nilton Campos, Praia Vermelha, CEP 22290-902, Rio de Janeiro- RJ , Brasil

Endereço eletrônico: fportugal@ufrj.br 
Recebido em: 09/10/2009

Aceito para publicação em: 05/01/2010

Acompanhamento do processo editorial: Rita Maria Manso de Barros

\section{Notas}

* Doutor em Psicologia pela PUC-Rio, Pós-doutorado no Science in Human Culture Program, Northwestern University, Evanston, Illinois, USA, Bolsista da Capes (Proc.4185/09-9).

${ }^{1}$ A nova edição faz parte do projeto Memória da Psicologia Brasileira, patrocinado pelo Conselho Federal de Psicologia e tem no Grupo de Trabalho em História da Psicologia da ANPEPP seu apoio. O projeto tem facilitado o acesso a textos históricos e elaborado análises críticas de seus personagens.

${ }^{2}$ Não há conhecimento de nenhum exemplar das obras Das alucinações auditivas dos “perseguidos" e 0 fato psíquico, ambas publicadas em 1904.

${ }^{3} \mathrm{O}$ trecho com aspas tipográficas é de João Ribeiro, escrito em A língua nacional. Neste ponto J oão Ribeiro defende enfaticamente a diferenciação da língua nacional em relação ao português de Portugal sob risco de ficar "vedado todo progresso nacional (progresso mental, bem se vê). Trata-se da independência de nosso pensamento e da sua imediata expressão." E faz um eloquente apelo: "Um inquérito mais largo viria abrir-nos um pouco os olhos contra a insuportável imposição de doutrinas puristas com que se pretende loucamente colorir o ambiente demasiadamente luminoso da América". 